\title{
The Value of Electrophoresis and Chemical Detection in the Diagnosis of Hypertensive Nephropathy
}

\author{
Xin Yang \\ Jun Fan \\ Yingzhi Wu \\ Jie Lin \\ Chongling Qian \\ Jing Li
}

Department of Laboratory Medicine, Kongjiang Hospital, Shanghai, 200093,

People's Republic of China
Correspondence: Xin Yang Department of Laboratory Medicine, Kongjiang Hospital, No. 480 Shuangyang Road, Yangpu District, Shanghai, 200093, People's Republic of China Tel/Fax +86 2165434597 Ext8136 Email xinyang_202I@2Icn.com
Objective: To investigate the clinical value of sodium dodecyl sulfate-agarose gel electrophoresis (SDS-AGE) of urinary proteins combined with several biochemical indices in the detection of hypertensive nephropathy.

Material and Methods: In this study, 210 patients with hypertensive nephropathy were recruited as the kidney disease group, 100 patients with simple hypertension were recruited as the hypertension group, and another 100 healthy participants were recruited as the control group. We conducted SDS-AGE of urinary proteins and urinary microalbumin (mAlb), $\beta_{2}$-microglobulin $\left(\beta_{2}-\mathrm{MG}\right)$, retinol-binding protein $(\mathrm{RBP})$, serum cystatin $\mathrm{C}(\mathrm{Cys} C)$, blood urea nitrogen (BUN), and creatinine tests at the same time.

Results: The results showed that the urinary mAlb levels in the hypertension group and hypertensive nephropathy group were higher than in the control group $(P<0.05)$. The biochemical index detection results showed that $\beta_{2}-\mathrm{MG}, \mathrm{RBP}$, serum $\mathrm{CysC}, \mathrm{BUN}$, and creatinine were higher in the hypertensive nephropathy group than in the control group and hypertension group $(P<0.05)$. The total positive rates of urinary protein SDS-AGE and urinary mAlb, urinary $\beta_{2}-\mathrm{MG}$, blood CysC, blood RBP, BUN, and creatinine in 210 patients with essential hypertension nephropathy were $100.0 \%, 98.6 \%, 32.8 \%, 98.6 \%, 21.0 \%, 2.0 \%$, and $20 \%$, respectively. The total positive rate of SDS-AGE urinary protein was higher than that of the other six biochemical indices.

Conclusion: SDS-AGE of urinary proteins, combined with urinary mAlb, $\beta_{2}-\mathrm{MG}$, serum CysC, RBP, BUN, and creatinine, could improve the detection sensitivity, which would be helpful for the early and accurate diagnosis of kidney damage.

Keywords: hypertension, kidney damage, sodium dodecyl sulfate-agarose gel electrophoresis, urinary mAlb, $\beta_{2}-\mathrm{MG}$, serum $\mathrm{CysC}, \mathrm{RBP}, \mathrm{BUN}$, pathological proteinuria

\section{Introduction}

Hypertension is a disease that often causes complications in the kidneys. ${ }^{1,2}$ Commonly used clinical biochemical detection methods for kidney disease include urinary microalbumin (mAlb), $\beta_{2}$-microglobulin $\left(\beta_{2}-\mathrm{MG}\right)$, serum retinol-binding protein (RBP), cystatin $\mathrm{C}(\mathrm{CysC})$, blood urea nitrogen (BUN), and creatinine. ${ }^{3-5}$ However, these biochemical detection methods are susceptible to certain factors outside the kidneys, their sensitivity is low, and there are limitations with these methods. ${ }^{6,7}$

Non-concentrated sodium dodecyl sulfate-agarose gel electrophoresis (SDSAGE) of urinary protein can separate the proteins of each component in the urine 
according to molecular weight, and can distinguish between physiological and pathological (glomerular, tubular, mixed) urinary protein types, with high sensitivity and specificity, as well as providing the location of kidney damage for the clinical diagnosis of hypertensive nephropathy. ${ }^{8}$

The value of SDS-AGE for hypertensive nephropathy remains unknown. We hypothesized that the combination of SDS-AGE and biochemical indices would have great clinical value in the detection of hypertensive nephropathy. Therefore, we conducted this study to investigate the clinical value of SDS-AGE combined with several biochemical indicators in the diagnosis of patients with hypertensive nephropathy.

\section{Materials and Methods}

\section{General Information}

From March 2015 to December 2017, patients with hypertension in Kongjiang Hospital of Yangpu District, Shanghai, were recruited. This study was approved by the ethics committee of Kongjiang Hospital of Yangpu District, Shanghai (KJ-2020-KY-19). All participants had signed informed consent before entering this study. This study was conducted in accordance with the Declaration of Helsinki. The diagnostic criteria for hypertension referred to the revised edition of the 2010 China Guidelines for the Prevention and Treatment of Hypertension: diastolic blood pressure $>90 \mathrm{mmHg}$ and systolic blood pressure $>140$ mmHg. Patients with secondary hypertension caused by malignant tumors, renal artery stenosis, coronary heart disease, diabetes, autoimmune diseases, and heart failure were excluded. Finally, 210 patients with hypertensive nephropathy were recruited as the kidney disease group, 100 patients with simple hypertension were recruited as the hypertension group, and another 100 healthy participants were recruited as the control group.

\section{Instruments}

An automatic electrophoresis instrument, HYDRAYS (Sebia, France), a TBA-120FR automatic biochemical analyzer (Toshiba, Japan), a BN prospect automatic specific protein analyzer (Siemens, Germany), and a Combi Scan 500 automatic urine analyzer (Combi-Screen, Germany) were used. The SDS-AGE urinary protein electrophoresis kit and acid violet dye were provided by Sebia, and the urine $\beta_{2}$-MG kit was provided by Siemens. Serum CysC, RBP, BUN, and creatinine kits were provided by Zhejiang
Ningbo Quark Biological Co. Ltd. The urinary mAlb test was provided by Shanghai Danli Biological Co., Ltd, and the Combi-Screen 11SYS test strip for qualitative urinary protein was provided by Combi-Screen.

\section{Methods}

A $5 \mathrm{~mL}$ sample of urine collected from patients in the morning was centrifuged to collect the supernatant. For blood samples, $5 \mathrm{~mL}$ of venous blood collected in the morning from patients who had been fasting was centrifuged to collect serum. Urine $\beta_{2}-\mathrm{MG}$ and blood RBP were detected using the immunoturbidimetric method. Blood CysC was detected using the latex-enhanced immunoturbidimetric method. Serum BUN and creatinine were detected using the enzymatic method. Urinary protein was qualitatively detected using the urine dry chemical method.

\section{SDS-AGE}

We took $20 \mu \mathrm{L}$ of SDS bromophenol blue diluent and added $80 \mu \mathrm{L}$ of the treated urine, mixed it well, added 5 $\mu \mathrm{L}$ via a pipette into a gel injection hole (five holes/plate), and left it to diffuse for 10 minutes. We then ran electrophoresis on an SDS-agarose gel; separated and dried it after electrophoresis; dyed it (acid violet); decolored, scanned, and edited the electrophoresis curve using a computer; and printed the final result. ${ }^{9}$

\section{Observation Indicators}

The main observation indicators included SDS-AGE, urine $\mathrm{mAlb}\left(>30 \mathrm{mg} / \mathrm{L}\right.$ is positive), urine $\beta_{2}-\mathrm{MG}(>1.8 \mathrm{mg} / \mathrm{L}$ is positive), serum CysC ( $>1.15 \mathrm{mg} / \mathrm{L}$ is positive), serum RBP ( $>70 \mathrm{mg} / \mathrm{L}$ is positive), BUN ( $>7.1 \mathrm{mmol} / \mathrm{L}$ is positive), and blood creatinine ( $>133 \mu \mathrm{mol} / \mathrm{L}$ is positive).

\section{Statistical Methods}

SPSS 20.0 statistical software was used for data analysis. Measurement data were expressed as the mean \pm standard deviation. A single-factor analysis of variance was used to compare multiple groups, and an SNK-q test was used for pairwise comparison between groups. $P<0.05$ was considered statistically significant.

\section{Results}

\section{General Characteristics}

The hypertensive nephropathy group consisted of 115 men and 95 women, aged 48-65 years, with an average age of 
$55.1 \pm 1.2$ years; the course of disease was 9-14 years, with an average of $10.4 \pm 1.2$ years. The simple hypertension group included 48 men and 52 women, aged 45-62 years, with an average age of $54.9 \pm 1.0$ years; the course of illness was $8-10$ years, with an average age of $9.6 \pm 1.4$ years. The control group included 63 men and 37 women, aged 45-62 years, with an average age of $55.0 \pm 1.3$ years. There were no statistically significant differences in gender and age among the three groups of subjects, and they were comparable $(P>0.05)$.

\section{Comparison of Biochemical Indicators of Subjects in Each Group}

The urinary mAlb levels of the simple hypertension group and the hypertensive nephropathy group were higher than in the control group. The urinary $\beta_{2}-\mathrm{MG}$, blood RBP, serum $\mathrm{CysC}, \mathrm{BUN}$, and blood creatinine in the hypertensive nephropathy group were higher than those in the control group and the simple hypertension group $(P<0.05)$ (Table 1$)$.

\section{Results of Urinary Protein Electrophoresis in Patients with Hypertensive Nephropathy}

Among the 210 patients with hypertensive nephropathy, there were 138 cases of glomerular proteinuria (graphically, in addition to the albumin zone, other protein zones appear between the sample point and the protein zone), accounting for $65.7 \%$; 31 cases of renal tubular proteinuria (graphically, in addition to the albumin zone, other protein zones appear between the anode of the gel sheet and the albumin zone), accounting for $14.8 \%$; and 41 cases of mixed proteinuria (characterized by the appearance of the above-mentioned protein zones), accounting for $19.5 \%$. Among the 100 patients with simple hypertension, 14 had physiological proteinuria (graphically, a small amount of lightly stained single albumin zone appears, and no other large or small molecular zones appear). Among the 100 healthy subjects, nine had physiological proteinuria (Figure 1).

\section{Evaluation and Comparison of Pathological Proteinuria Types After Urinary SDS-AGE in Patients with Hypertensive Nephropathy}

There were 138 cases of glomerular proteinuria, consisting mainly of medium-sized molecules (albumin $70 \times 10^{3}$ ), and large molecules (transferrin $80 \times 10^{3}$, IgA $175 \times 10^{3}$, IgG $\left.160 \times 10^{3}\right)$; 31 cases of renal tubular proteinuria, consisting mainly of medium-sized molecules (albumin $70 \times 10^{3}$ ) and small molecules (free light chain dimer $50 \times 10^{3}$, free light chain $25 \times 10^{3}$, RBP $21 \times 10^{3}, \alpha_{1}$-microglobulin $33 \times 10^{3}$, lysozyme $15 \times 10^{3}, \beta_{2}$-MG $12 \times 10^{3}$ ); and 41 cases of mixed proteinuria, consisting mainly of medium-sized molecules (albumin $70 \times 10^{3}$ ), large molecules (transferrin $80 \times 10^{3}, \operatorname{IgA} 175 \times 10^{3}$, IgG $160 \times 10^{3}$ ), and small molecules (free light chain dimer $50 \times 10^{3}$, free light chain $25 \times 10^{3}$, RBP $21 \times 10^{3}, \alpha_{1^{-}}$ microglobulin $33 \times 10^{3}$, lysozyme $15 \times 10^{3}, \beta_{2}$-MG $12 \times 10^{3}$ ) (Figure 2).

\section{Comparison of Biochemical Indicators of Different Types of Proteinuria in Patients with Hypertensive Nephropathy}

The total positive detection rates of different types of proteinuria in urine $\mathrm{mAlb}$, urine $\beta_{2}-\mathrm{MG}$, blood CysC, serum RBP, BUN, and blood creatinine were 99.0\%, $32.8 \%, 99.0 \%, 21.0 \%, 2.0 \%$, and $20 \%$, respectively.

Table I Comparison of Biochemical Index Results for Subjects in Each Group (mean \pm SD)

\begin{tabular}{|l|l|l|l|l|l|l|l|}
\hline Group & $\begin{array}{l}\text { Number } \\
\text { of Cases }\end{array}$ & Urine mAlb & Urine $\boldsymbol{\beta}_{2}$-MG & Blood CysC & Serum RBP & BUN & $\begin{array}{l}\text { Blood } \\
\text { Creatinine }\end{array}$ \\
\hline Control group & 100 & $14.50 \pm 0.87$ & $1.64 \pm 0.15$ & $0.79 \pm 0.16$ & $41.67 \pm 0.79$ & $4.58 \pm 0.66$ & $84.59 \pm 7.05$ \\
\hline $\begin{array}{l}\text { Simple hypertension } \\
\text { group }\end{array}$ & 100 & $16.29 \pm 1.66^{\mathrm{a}}$ & $1.79 \pm 0.25$ & $0.83 \pm 0.17$ & $43.48 \pm 1.28$ & $4.48 \pm 0.66$ & $85.49 \pm 8.53$ \\
\hline $\begin{array}{l}\text { Hypertensive } \\
\text { nephropathy group }\end{array}$ & 210 & $49.50 \pm 1.82^{\mathrm{ab}}$ & $5.01 \pm 2.14^{\mathrm{ab}}$ & $2.95 \pm 0.32^{\mathrm{ab}}$ & $118.35 \pm 8.93^{\mathrm{ab}}$ & $6.96 \pm 0.62^{\mathrm{ab}}$ & $120.02 \pm 5.42^{\mathrm{ab}}$ \\
\hline value & & $23,345.54$ & 234.64 & 3563.23 & 6993.73 & 739.53 & 1397.09 \\
\hline$P$ value & & $<0.001$ & $<0.001$ & $<0.001$ & $<0.001$ & $<0.001$ & $<0.00 \mathrm{I}$ \\
\hline
\end{tabular}

Notes: ${ }^{a} P<0.05$ vs the control group; ${ }^{b} P<0.05$ vs the simple hypertension group.

Abbreviations: mAlb, microalbumin; $\beta_{2}$-MG, $\beta_{2}$-microglobulin; RBP, retinol-binding protein; CysC, cystatin C; BUN, blood urea nitrogen. 


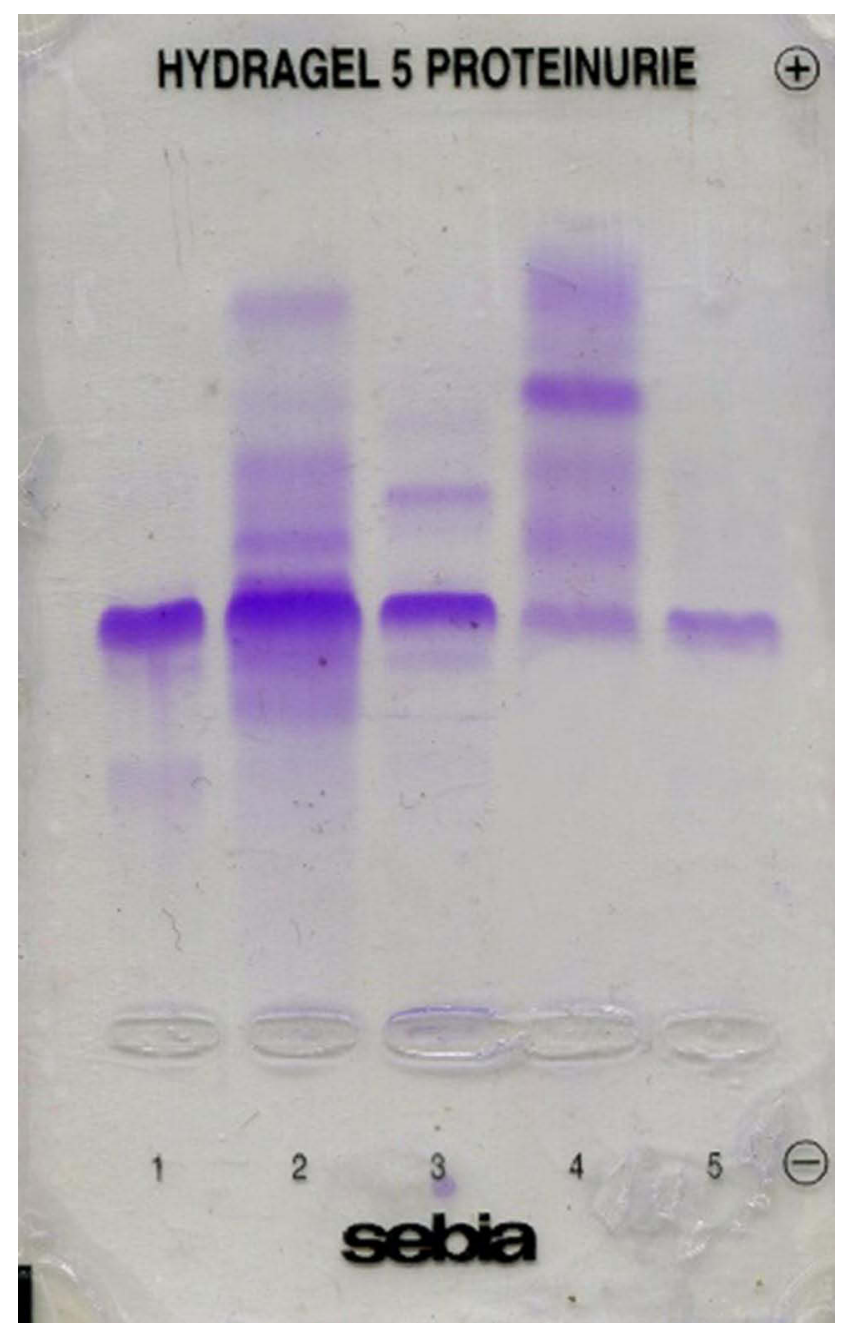

Figure I SDS-AGE urinary protein electrophoresis pattern. I: Glomerular proteinuria; 2: mixed proteinuria; 3: mixed proteinuria; 4: renal tubular proteinuria; 5: physiological proteinuria.

The sensitivity of blood $\mathrm{CysC}$ and urinary mAlb in all types of hypertensive nephropathy was high, and the sensitivity of urinary $\beta_{2}-\mathrm{MG}$, serum RBP, BUN, and blood creatinine in all types of hypertensive nephropathy was not high (Table 2).

\section{Discussion}

The biochemical index test is a chemical method in which internal and external factors can easily interfere with the test, often requiring the use of simultaneous testing of several indicators. ${ }^{10-12}$ Urinary mAlb, urinary $\beta_{2}-\mathrm{MG}$, serum $\mathrm{RBP}$, and CysC detection methods are common diagnostic methods for hypertensive nephropathy, ${ }^{13-19}$ The results of this study show that the urinary mAlb levels of the simple hypertension group and the hypertensive nephropathy group were higher than in the control group. The urinary $\beta_{2}-\mathrm{MG}$, blood RBP, serum CysC, BUN, and blood creatinine of the hypertensive nephropathy group were higher than in the control group and simple hypertension group. The results showed that these indices can be used in the diagnosis of hypertensive nephropathy.

In this study, the evaluation of pathological proteinuria types confirmed that 138 cases of glomerular proteinuria consisted mainly of medium-sized molecules (albumin) and large molecules (transferrin, IgA, IgG); 31 cases of renal tubular proteinuria consisted mainly of mediumsized molecules (albumin) and small molecules (free light chain dimer, free light chain, RBP, $\alpha_{1}$ microglobulin, lysozyme, $\beta_{2}-\mathrm{MG}$ ); and 41 cases of mixed proteinuria consisted mainly of medium-sized molecules (albumin), large molecules (transferrin, IgA, IgG), and small molecules (free light chain dimer, free light chain, RBP, $\alpha_{1}$-microglobulin, lysozyme, $\beta_{2}-\mathrm{MG}$ ). The results of this study showed that the sensitivity of blood CysC and urinary $\mathrm{mAlb}$ in all types of hypertensive nephropathy was high, and the sensitivity of urinary $\beta_{2}-\mathrm{MG}$, serum RBP, BUN, and blood creatinine in all types of hypertensive nephropathy was not high. It is very important to improve the sensitivity of the diagnosis of hypertensive nephropathy.

Urinary protein SDS-AGE has not yet seen widespread use. ${ }^{20}$ Although urinary mAlb and serum CysC can significantly detect changes in the course of hypertensive nephropathy, they cannot reflect the location of kidney damage and the source of urinary protein. SDSAGE of urinary proteins can reflect the location of kidney damage in hypertensive nephropathy. ${ }^{9}$ The main detection principle of urinary protein SDS-AGE is that SDS negatively ionized surfactants connect with urinary proteins to form negatively charged SDS-protein complexes. The morphology of the protein itself in these protein complexes has been destroyed, and they all show the same structure and the same negative charge. When such SDS-protein complexes are electrophoresed using agarose gel film, with appropriate screening characteristics, they will be separated according to the difference in protein molecular weight. On the agarose gel film, the renal tubular proteins (ie, molecular weight $<65$ to 70,000 ) and glomerular proteins (ie, molecular weight $>65$ to 70,000 ) will be clearly separated. Therefore, not only can proteinuria be detected, but it can also be classified according to the detected proteins (such as renal tubulin, glomeruli, and their mixtures). 


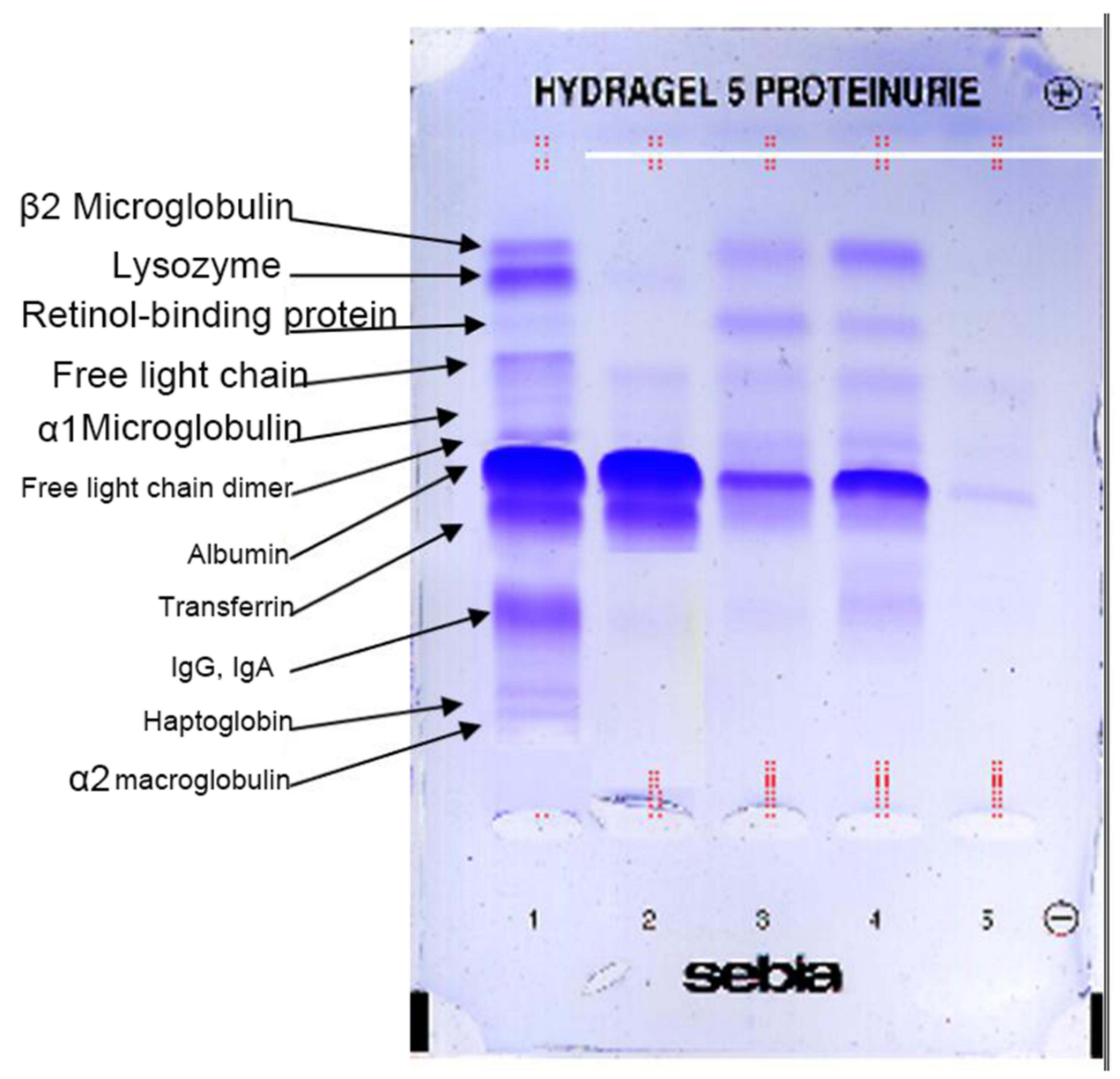

Figure 2 Molecular composition of pathological proteinuria after SDS-AGE. I: Mixed proteinuria; 2: renal tubular proteinuria; 3: renal tubular proteinuria; 4: mixed proteinuria; 5: physiological proteinuria.

The analytical parameters and sensitivity of crystal violet coloring solution can be used for protein detection without the need to concentrate urine samples. The lowest detectable concentration in each zone is approximately $0.15 \mathrm{mg} / \mathrm{L} .{ }^{9}$

\section{Conclusions}

Urinary protein SDS-AGE can assist in determining the nature of proteins in the urine, and assist in the clinical differentiation of renal lesions. SDS-AGE of urinary proteins, combined with urinary $\mathrm{mAlb}, \beta_{2}-\mathrm{MG}$, serum

Table 2 Comparison of Biochemical Indices of Different Types of Proteinuria in Patients with Hypertensive Nephropathy ( $\mathrm{n}=210$ )

\begin{tabular}{|c|c|c|c|c|c|c|c|}
\hline \multirow{2}{*}{$\begin{array}{l}\text { SDS-AGE Urinary Protein } \\
\text { Electrophoresis }\end{array}$} & \multirow[t]{2}{*}{$\mathbf{n}$} & \multicolumn{6}{|c|}{ Number of Positive Cases, n (\%) } \\
\hline & & $\begin{array}{l}\text { Urine } \\
\text { mAlb }\end{array}$ & $\begin{array}{l}\text { Urine } \beta_{2^{-}} \\
\text {MG }\end{array}$ & $\begin{array}{l}\text { Blood } \\
\text { CysC }\end{array}$ & $\begin{array}{l}\text { Serum } \\
\text { RBP }\end{array}$ & BUN & $\begin{array}{c}\text { Blood } \\
\text { Creatinine }\end{array}$ \\
\hline Glomerular proteinuria & 138 & $138(100)$ & $2(1.4)$ & $138(100)$ & $3(2.2)$ & $4(2.9)$ & $2(1.4)$ \\
\hline Renal tubular proteinuria & 31 & $29(93.5)$ & $29(93.5)$ & $29(93.5)$ & $12(38.7)$ & I (3.2) & $4(12.9)$ \\
\hline Mixed proteinuria & 41 & $41(100)$ & $38(92.7)$ & $41(100)$ & $29(70.7)$ & $39(95.1)$ & $35(85.4)$ \\
\hline Total & 210 & $208(99.0)$ & $69(32.8)$ & $208(99.0)$ & $44(21.0)$ & $44(21.0)$ & $4 \mid(19.5)$ \\
\hline
\end{tabular}

Abbreviations: mAlb, microalbumin; $\beta_{2}$-MG, $\beta_{2}$-microglobulin; RBP, retinol-binding protein; CysC, cystatin C; BUN, blood urea nitrogen. 
CysC, RBP, BUN, and creatinine, could improve the detection sensitivity, which will be helpful for the early and accurate diagnosis of kidney damage.

\section{Disclosure}

All authors report no conflicts of interest for this work.

\section{References}

1. Haoming H, Zhaozeng W, Lin Z. New Essentials for Prevention and Treatment of Hypertension [M]. Shanghai: Tongji University Press; 2006:204-210.

2. China Committee for Revision of Guidelines for Prevention and Treatment of Hypertension. China guidelines for prevention and treatment of hypertension 2010. Chin J Cardiovasc Dis. 2011;39 (7):579-615.

3. Chuanyu X, Wenhua H, Qiang X, et al. The diagnostic significance of combined detection of serum $\beta_{2}$-microglobulin and cystatin $\mathrm{C}$ on hypertensive nephropathy. Chin Lab Diagn. 2017;21(4):645-646.

4. Hong Z, Ge X. Significance of Cys-C, BUN, sCr in the assessment of early renal injury of acute glomeruli. J Hainan Med Univ. 2016;22 (5):447-449.

5. Yugang $\mathrm{L}$. The clinical application of blood retinol binding proteinuria $\alpha_{1}$ microglobulinuria and urine microalbumin test in the early diagnosis of diabetic hypertension and nephropathy. J Pract Med Tech. 2016;23(10):1059-1061.

6. Mingjing W, Shanding Y. Clinical Laboratory Science [M]. Beijing: Science and Technology Literature Press; 1994:148-160.

7. Yufang W, Xiaodong G. Determination of urine protein in patients with kidney disease and comparative analysis of pathological biopsy. Mod Prev Med. 2007;34(4):56-58.

8. Xia S. Current status and development of electrophoresis technology. Chin J Lab Med. 2010;33(11):120-121.

9. Shen B, Lingge $X$, Xuejiao $C$, et al. Comparative study of non-concentrated urine protein electrophoresis and other urine protein detection methods. Lab Med. 2005;20(5):481-482.
10. Yang Z. Changes of serum CRP, cystatin C and urinary microalbumin in patients with essential hypertensive nephropathy and analysis of their clinical significance. Chin Pract Diagn. 2015;19(3):407-409.

11. Xiansong C, Jing D. The value of combined detection of U-mAlb, serum Cys-C and serum Hcy in the early diagnosis of hypertensive nephropathy. J Lab Med Clin Med. 2017;14(18):2770-2772.

12. Penghui T. The significance of combined detection of cystatin $\mathrm{C}$ and $\beta 2$-microglobulin in the early diagnosis of diabetic nephropathy. Diabetes New World. 2015;35(18):31-33.

13. Wencheng L, Guoke L, Xiaokun Z, et al. The diagnostic value of combined analysis of renal function indexes for early renal damage in elderly hypertension. Int J Lab Med. 2008;29(6):512-514.

14. Xuehua Y, Weiwei Z, Quanlun L, et al. Clinical significance of combined detection of serum retinol binding protein, cystatin $\mathrm{C}$ and $\beta_{2}$-microglobulin in the diagnosis of early renal damage in gestational diabetes. J Mod Lab Med. 2017;32(2):106-109.

15. Li L. The clinical significance of detecting 4 microproteins in urine on early hypertensive renal damage. Fujian Med J. 2003;25 (5): 13-14.

16. Lixia X, Juan C, Yufeng M, et al. The value of Cys-C and inflammatory factors in the early diagnosis and evaluation of hypertension. Chin Med Guide. 2017;19(8):768-770.

17. Jing Q, Rong W, Xia S, et al. Application of combined detection of cystatin $\mathrm{C}$, urinary microalbumin, and $\beta_{2}$-microglobulin in the diagnosis of early renal injury in diabetes. Chin Lab Diagn. 2016;20 (3):439-441.

18. Yan J, Rushi L, Yilan Q, et al. Significance of combined detection of serum cystatin $\mathrm{C}$ and homocysteine in the diagnosis of early nephropathy of hypertension. Chongqing Med. 2015;44(9):1193.

19. Qifeng H, Lunshan W, Jianan J, et al. The diagnostic value of combined detection of urine microalbumin, serum cystatin $\mathrm{C}$ and serum homocysteine in early hypertensive nephropathy. Anhui Med. 2015;19(7):1361-1362.

20. Ying W, Yong H, Xiaorong Z, et al. Urine protein electrophoresis analysis and mass spectrometry identification. Mod Med Health J. 2016;32(12):1803-1805.
International Journal of General Medicine

\section{Publish your work in this journal}

The International Journal of General Medicine is an international, peer-reviewed open-access journal that focuses on general and internal medicine, pathogenesis, epidemiology, diagnosis, monitoring and treatment protocols. The journal is characterized by the rapid reporting of reviews, original research and clinical studies

\section{Dovepress}

across all disease areas. The manuscript management system is completely online and includes a very quick and fair peer-review system, which is all easy to use. Visit http://www.dovepress.com/ testimonials.php to read real quotes from published authors. 